\title{
BMJ Open Effects of school-based intervention by emergency medical technicians on students and their parents: a community-based prospective study of the Akashi project
}

\author{
Shinya Tomari, ${ }^{1}$ Chiaki Yokota, ${ }^{1}$ Kunihiro Nishimura, ${ }^{2}$ Tenyu Hino, ${ }^{1}$ \\ Satoshi Ohyama, ${ }^{1}$ Takuro Arimizu, ${ }^{1}$ Shinichi Wada, ${ }^{1}$ Hideyuki Ohnishi, ${ }^{3}$ \\ Kazunori Toyoda, ${ }^{1}$ Kazuo Minematsu ${ }^{1}$
}

To cite: Tomari S, Yokota C, Nishimura K, et al. Effects of school-based intervention by emergency medical technicians on students and their parents: a communitybased prospective study of the Akashi project. BMJ Open 2017;7:e016780. doi:10.1136/ bmjopen-2017-016780

- Prepublication history for this paper is available online. To view these files please visit the journal online (http://dx.doi. org/10.1136/bmjopen-2017016780).

Received 14 March 2017 Accepted 26 July 2017

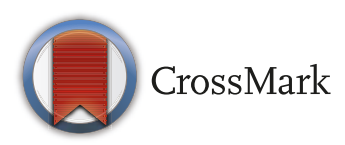

${ }^{1}$ Department of Cerebrovascular Medicine, National Cerebral and Cardiovascular Center, Suita, Japan

${ }^{2}$ Department of Preventative Medicine and Epidemiology, National Cerebral and Cardiovascular Center, Suita, Osaka, Japan

${ }^{3}$ Ohnishi Neurological Center, Akashi, Japan

Correspondence to Dr Chiaki Yokota; cyokota@ncvc.go.jp

\section{ABSTRACT}

Objective Stroke lessons for youth provided by emergency medical technicians (EMTs) may be an effective strategy to facilitate early intervention for patients with stroke. The aim of this study was to examine how effective EMT-led lessons on stroke awareness for schoolchildren were at disseminating stroke information.

Setting, participants and outcome measures The study was performed in the city of Akashi, Hyogo, Japan (Akashi project). Children (aged 9-10years old) at 11 public elementary schools and their parents were enrolled in this study. EMTs from the firefighting headquarters provided lessons on stroke to the children using our educational materials between September 2014 and October 2015 Each child was given our educational materials to take home and discuss stroke with their parents. The children and their parents answered questionnaires on stroke knowledge before, immediately and at 3 months after the lesson.

Results A total of 763 children and 489 parents were enrolled (ie, $64 \%$ of children). The scores of either stroke symptoms or risk factors were significantly higher immediately and at 3 months after the lesson, compared with before the lesson, both in children and the parents $(p<0.01)$. Compared with the baseline in both groups (58\% in children, $83 \%$ in parents), the meaning of the FAST mnemonic at 3 months $(88 \%, 94 \%)$, as well as at immediately after the lesson (90\%, 89\%), was significantly higher $(p<0.001)$.

Conclusion Stroke education by EMTs was effective in increasing stroke awareness in elementary school children, as well as their parents.

\section{INTRODUCTION}

Reducing the time from stroke onset to arrival at the hospital is essential to improving stroke outcome. Improvement in the accuracy of diagnosis of stroke by paramedics through a multilevel educational programme for emergency medical
Strengths and limitations of this study

- This is the first report to reveal that children can gain knowledge about stroke, via a lesson conducted by emergency medical technicians (EMTs) using our educational materials, which they can subsequently pass on to their parents.

- We could not illustrate the change in the number of patients with stroke to a stroke unit or detect behavioural changes in calling an ambulance on recognition of suspected stroke symptoms.

- However, the results of the present study indicate that the close collaboration with EMTs to improve the accuracy of diagnosis of stroke is a promising approach to reduce the time from stroke onset to arrival at the hospital.

technicians (EMTs), hospital staff and citizens increased the number of patients presenting for evaluation within the therapeutic time frame for acute thrombolytic therapy. ${ }^{1}$ Stroke educational campaigns for elementary school or junior high school students have been demonstrated to be effective not only for the youth, but also, indirectly, for their families through communication among family members. ${ }^{2-4}$ In Japan, school-based intervention for a fire safety campaign or to teach first-aid for heart attack is usually performed by EMTs once a year in most elementary schools. The Akashi project, a school-based campaign of stroke education, was initially proposed by the EMTs at the firefighting headquarters in Akashi city. They attempted to raise awareness of calling an emergency medical service (EMS) on recognition of stroke symptoms, through a school-based campaign. Therefore, we collaborated with EMTs to 
investigate whether stroke lessons provided by EMTs to youth could be effective in facilitating the dissemination of stroke information to students and their families. Increased stroke knowledge may facilitate the early arrival of stroke victims to a stroke centre following the onset of stroke symptoms.

An aim of the current study was to examine if the use of EMTs to teach stroke awareness to elementary school children has an impact on emergent care.

\section{METHODS}

This study was approved by our institutional review board and was registered with the UMIN clinical trial (ID: UMIN000018245). Akashi city, urban area of Hyogo prefecture, is designated as 'City of Meridian' in Japan, which is in the east longitude $135^{\circ}$, and has approximately 290000 residents. There are 28 public elementary schools and approximately 2500 elementary school children (aged 9-10 years old) in Akashi city. The current study cohort consisted of 887 elementary school children from 11 public elementary schools, and their parents (father, mother or other guardian) in Akashi city. After receiving a lesson on stroke by a specialised stroke neurologist using our educational material for junior high school students, ${ }^{5}$ the EMTs at the firefighting headquarters created a stroke lesson plan and instructed the children between September 2014 and October 2015. A total of 50 EMTs were involved with the instruction programme. The stroke lecture consisted of two lessons performed continuously in the same day. In the first lesson, the EMTs used our educational materials for elementary school children, showing an animated cartoon $^{6}$ (figure 1A). In the second lesson, the children participated in a simulation of the experience of a stroke patient with haemiparesis: the children walked with an arm and leg restricted on one side in the gymnasium. At the end of the lecture, all the children were given a Manga (comic book; figure 1B), a magnet poster, both of which were developed for elementary school children, ${ }^{6}$ and a questionnaire for their parents. The magnet poster showed the FAST mnemonic derived from the Cincinnati prehospital stroke scale: F, face numbness or weakness; A, arm numbness or weakness; S, speech slurred or difficulty speaking or understanding; T, Time to call ambulance. ${ }^{7}$ EMTs instructed the children to take the materials home and talk about stroke with their parents and to put the magnet poster on the refrigerator to share with their family.

For the assessment, a multiple-choice and closed-type questionnaire on stroke knowledge was prepared (box). Regarding stroke symptoms, seven items were presented and consisted of three correct and four incorrect items.

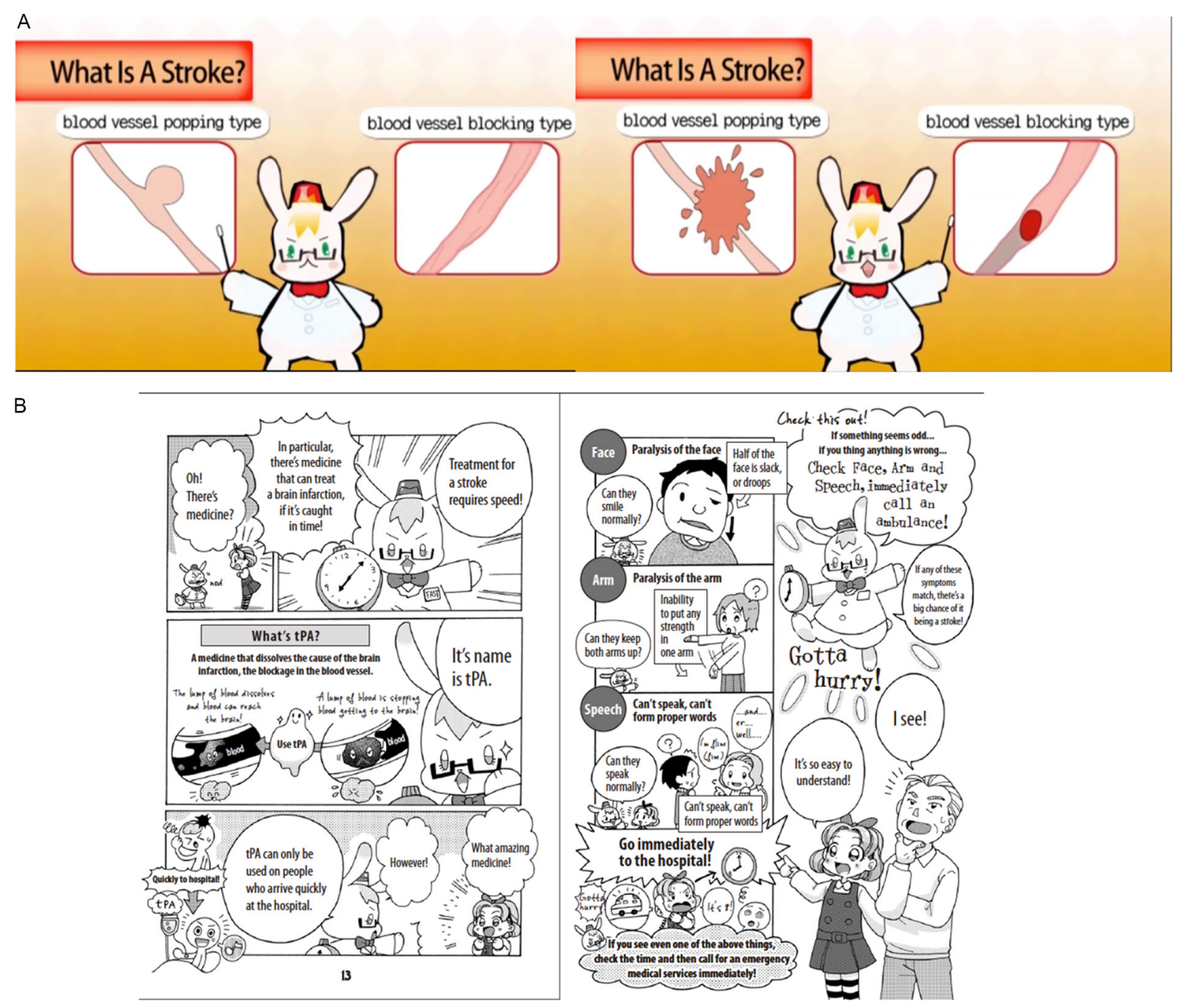

Figure 1 Stroke education materials for elementary school children. (A) A sample of an animated cartoon for stroke education. Original aids were written in Japanese. (B) A sample of a comic book (Manga). Original aids were written in Japanese. 


\section{Box Questionnaire given to the children and their parents}

Question 1: Which symptoms do you think people with a stroke are most likely to show?

A. Facial weakness on one side

B. Fart

C. Shoulder pain

D. Speaking unclearly

E. Fever

F. Weakness of arm and leg on one side of the body

G. Stomach ache

Question 2: What do you do if you find a person who is having a stroke?

A. Take him/her to the nearest hospital in a taxi or a bus.

B. Tell him/her to go to his/her personal doctor tomorrow.

C. Call an ambulance

D. Tell him/her to rest.

Question 3: What do you think is the likely cause of stroke?

A. Hypertension

B. High cholesterol level

C. Back pain

D. Heavy alcohol drinking

E. Constipation

F. Smoking

G. Welfare

Question 4: What is the meaning of the 'FAST' mnemonic?

I. What is a stroke symptom in a person's face?

A. Smile

B. Facial weakness on one side

C. Face drooping on both sides

II. What is a stroke symptom in a person's arm?

A. Weakness of arm on one side

B Weakness of arms on both sides

C. Fracture of the arm

III. What is a stroke symptom in a person's speech?

A. Talkative

B. Speaking unclearly

C. Foul language

Correct answers are in bold.

For calculating scores, participants received a point if they chose a correct item or did not choose an incorrect item. The score of questionnaires on stroke symptoms ranged from 0 to 7 points. A question concerning the first step that should be taken on recognition of stroke symptoms in an individual was asked as a single-choice test. Regarding risk factors, the seven items consisted of four correct and three incorrect items. The scores were calculated as well as questionnaires on stroke symptoms and ranged from 0 to 7 . The meaning of the FAST mnemonic was asked as a single-choice test. Participants were then questioned about the symptoms of stroke associated with the 'Face', 'Arm' and 'Speech', and received a correct score if they chose the right answer in all three of the questions. The children and their parents took the same questionnaires within 2 weeks before the lesson, immediately after the lesson and at 3 months post-lesson. A letter of request to answer questionnaires for parents were carried to home by children in each time point. Questionnaires answered by the parents were taken to the school by their children and collected by the schoolteachers.

We collected the individual results of questionnaires at each time point using an anonymous student identification number assigned to each child. The results of the questionnaires in each group collected before the lesson were compared with those acquired immediately and 3 months after the lesson, using Fisher's exact test. In each questionnaire on stroke symptoms and risk factors, we conducted mixed model analysis using an anonymous number of children as a random intercept to adjust for autocorrelation of individuals using the mixed command in STATA. All statistical tests were two-sided and statistical significance was set at $\mathrm{p}<0.05$. All statistical analyses were performed using JMP 8 (SAS Institute, Cary, North Carolina, USA) or STATA software, V.13.0 (Stata Corp, College Station, Texas, USA).

\section{RESULTS}

A total of 124 children and 398 parents who did not complete questionnaires at 3 months were excluded. Thus, data from 763 children and 489 parents were analysed (figure 2). The score of questionnaires on stroke symptoms and risk factors ranged from 0 to 7 points. The expected values of both questionnaires were 3.5. The adjusted mean scores of the questionnaires on stroke symptoms/risk factors by mixed model at before, immediately and at 3 months after the lesson in children were 5.84/5.54, 6.92/6.79 and 6.80/6.33, respectively (figure 3 ). The adjusted mean scores of the parents at before, immediately and at 3 months after the lesson were $6.42 / 5.74,6.91 / 6.56$ and $6.85 / 6.35$, respectively. The adjusted mean total test scores of children/parents at before, immediately and at 3 months after the lesson were $11.44 / 12.13,13.78 / 13.46$ and 13.22/13.21, respectively. In both groups, the scores of stroke symptoms, risk factors or total score at immediately and at 3 months after the lesson were significantly higher than those at before the lesson $(p<0.01)$. The correct answer rates of how to act on recognition of stroke symptoms (figure $4 \mathrm{~A}$ ): $83 \% / 97 \% / 89 \%$ before/immediately/3 months after the lesson in children; $87 \% / 96 \% / 93 \%$ in parents and the meaning of the FAST mnemonic at immediately and at 3 months after the lesson (figure 4B); and 58\%/90\%/88\% in children, $83 \% / 89 \% / 94 \%$ in parents were also significantly higher than those at before the lesson in both the children and their parents $(\mathrm{p}<0.001)$.

\section{DISCUSSION}

We demonstrated that elementary school children were able to learn about stroke through the lessons provided by the EMTs. The schoolchildren were consequently able to transfer the knowledge gained to their parents. Furthermore, the children and their parents could recall stroke symptoms, risk factors and the meaning of FAST mnemonic, at even 3 months after the stroke lessons. 


\section{Children}

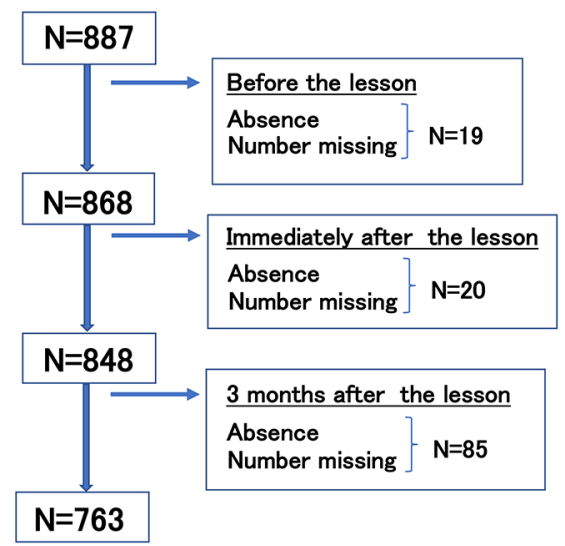

Parents

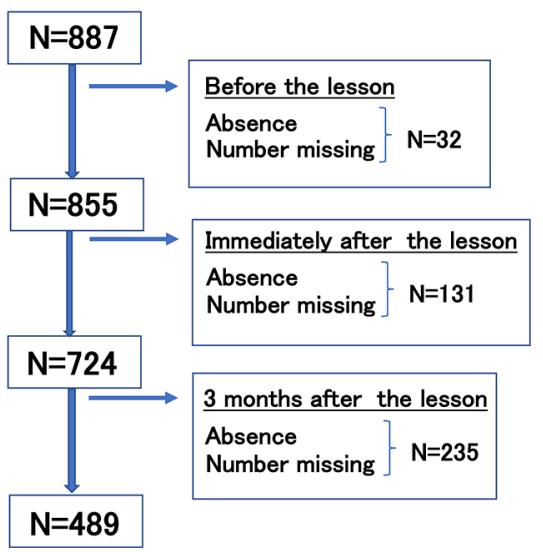

Figure 2 Causes of exclusion from the study. A total of 124 children and 398 parents, who did not complete questionnaires at 3 months, were excluded from the total of 887 children and their parents who were recruited for the study. Thus, data from 763 children and 489 parents were analysed in the present study.

The effectiveness of school-based interventions to deliver stroke knowledge and awareness to junior high school students has been previously demonstrated. ${ }^{2}$ 3 5 5 $8-10$ School-based interventions for cardiovascular diseases or other lifestyle-related diseases are also considered promising. ${ }^{11}{ }^{12}$ EMT-led lessons, which include experience-based learning and educational materials that are developed for elementary school children, are more likely to have favourable outcomes.

Agyeman et $a l^{13}$ demonstrated that EMTs can provide a fast means of transportation of stroke patients to a stroke unit. Several reports have examined EMTs-based interventions for identification of stroke. Some of these reports demonstrated that educational programme or prehospital protocols for EMTs improved the diagnosis

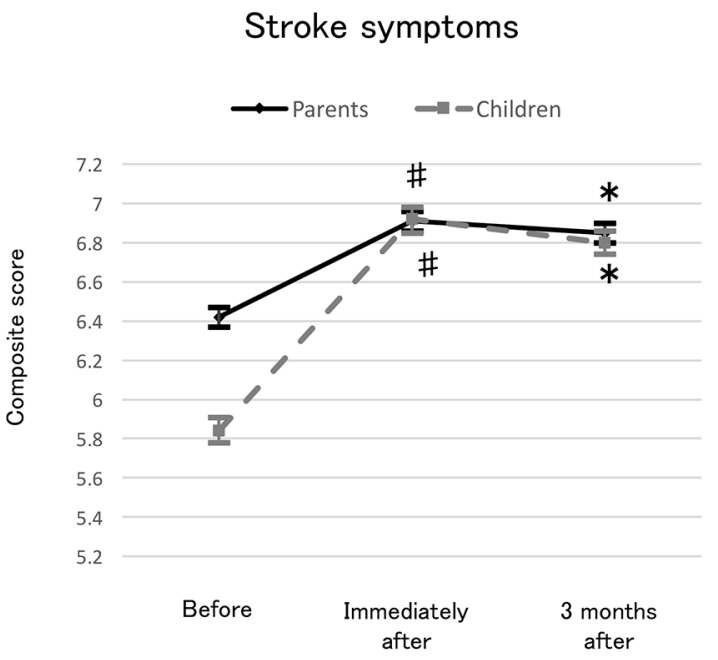

of stroke by paramedics and increased the victim's access to stroke thrombolysis, ${ }^{14-17}$ although a lack of impact of paramedic training was reported. ${ }^{18} 19$ The Akashi project intended to educate not only elementary school children and their parents on stroke, but the EMTs as well, in an attempt to decrease the arrival time to a hospital by improving the diagnosis of stroke by paramedics. Our findings suggested that stroke education delivered to youth by EMTs across the country is an effective strategy to spread stroke knowledge.

In the present study, correct answer rates of stroke sign and risk factors at baseline in children were approximately $80 \%$ and those in their parents were $80 \%-90 \%$. In comparison, in our previous study, the correct answer rates were $60 \%-70 \%$ and approximately $80 \%$ in children

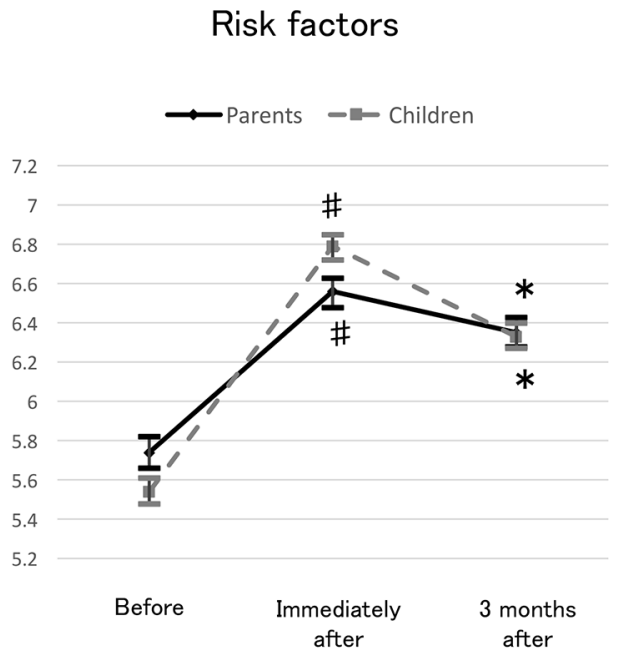

\#:p<0.01, vs. Before

Figure 3 Changes in the adjusted mean scores of the questionnaires on stroke symptoms/risk factors by mixed model in children and parents. The adjusted mean scores of both symptoms and risk factors at immediately and at 3 months after the stroke lesson were significantly higher, compared with those before the lesson in children and parents. 


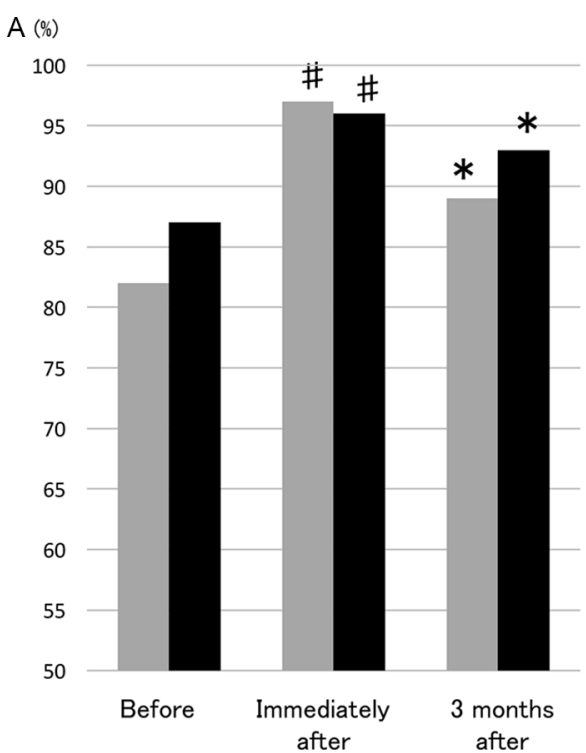

B

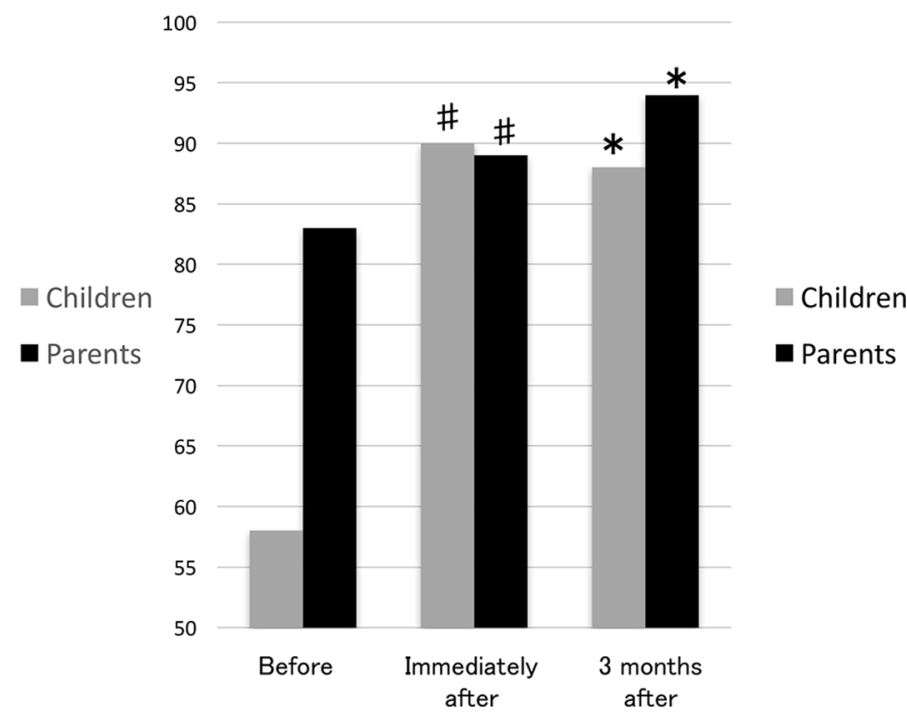

$\#: p<0.001$, vs. Before
$*: p<0.001$, vs. Before

Figure 4 (A) Proportion of children and parents selecting 'call an ambulance' on recognition of stroke symptoms before, immediately and at 3 months after the lesson. The proportion of correct answer rate at immediately, as well as at 3 months after was significantly higher than that before the lesson in both children and parents. (B) Correct answer rates of 'FAST' mnemonic before, immediately and at 3 months after the lesson. In both children and parents, correct answer rates at immediately and at 3 months after the lesson were significantly higher than those at before the lesson.

and their parents, respectively. ${ }^{6}$ We think that a high level of stroke knowledge at baseline could be due to higher level of stroke incidence in Japan.

Limitations of the currents study include the high loss of enrolment during parent follow-up, and the small sample size, which only includes a third of elementary children (aged 9-10years old) in Akashi City and only $0.4 \%$ of all its citizens. To reduce the concern of bias, we conducted a mixed model analysis using an anonymous number of children as a random intercept. Further, we were unable to illustrate the change in the number of stroke patients dispatched to a stroke unit or to detect behavioural changes in calling an ambulance on recognition of suspected stroke symptoms, due to the cross-sectional design of this study. A lack of association between stroke symptom knowledge and intent to call EMS was reported from a population-based survey. ${ }^{20}$ Further, the enhanced stroke knowledge seen in the parent cohort could be attributable to other informational sources such as television or newspapers, instead of resulting from communication with their children alone. There were no other local campaigns to increase stroke knowledge during the study period except 7 days of a stroke awareness week, held from May 25 to May 31 by the Japan stroke association every year. The best way to circumvent this limitation is to perform a randomised trial as reported previously. ${ }^{21}$ Further study is required to clarify if the time from symptom onset to the arrival at a stroke unit can be shortened and if patient outcome can be improved because of the Akashi project.
In conclusion, a school-based intervention to deliver knowledge about stroke by EMTs in the Akashi project was implemented successfully for elementary school children, and the stroke information was passed to their parents as well. In addition to increasing the awareness of stroke symptoms in the general population, the close collaboration with EMTs to improve the accuracy of diagnosis of stroke is essential in reducing the time from stroke onset to arrival at the hospital. We hope to continue the Akashi project, and share this project with EMTs around the world.

Acknowledgements The authors express our deepest gratitude to all members in the firefighting headquarters in Akashi, the teachers in public elementary schools in Akashi and Professor Keiko Takemiya (President of Kyoto Seika University, Kyoto, Japan).

Contributors $\mathrm{CY}$ and $\mathrm{KM}$ : designed the study. ST, TH, TA, SW and HO: collected the data. ST and KN: analysed the data. CY, KT and KM: interpreted the data. ST and SO: did the literature search. ST, CY and KM: wrote the manuscript. KT and KM: reviewed the report.

Funding This study was supported by the Intramural Research Fund of the National cerebral and cardiovascular center (27-1-3).

\section{Competing interests None declared.}

Ethics approval This study was approved by our institutional review board. Provenance and peer review Not commissioned; externally peer reviewed. Data sharing statement To access the data, contact the corresponding author.

Open Access This is an Open Access article distributed in accordance with the Creative Commons Attribution Non Commercial (CC BY-NC 4.0) license, which permits others to distribute, remix, adapt, build upon this work non-commercially, and license their derivative works on different terms, provided the original work is properly cited and the use is non-commercial. See: http://creativecommons.org/ licenses/by-nc/4.0/ 
(c) Article author(s) (or their employer(s) unless otherwise stated in the text of the article) 2017. All rights reserved. No commercial use is permitted unless otherwise expressly granted.

\section{REFERENCES}

1. Wojner-Alexandrov AW, Alexandrov AV, Rodriguez D, et al. Houston paramedic and emergency stroke treatment and outcomes study (HoPSTO). Stroke 2005;36:1512-8.

2. Amano T, Yokota C, Sakamoto $\mathrm{Y}$, et al. Stroke education program of act FAST for junior high school students and their parents. J Stroke Cerebrovasc Dis 2014;23:1040-5

3. Matsuzono K, Yokota C, Takekawa H, et al. Effects of stroke education of junior high school students on stroke knowledge of their parents: Tochigi project. Stroke 2015;46:572-4.

4. Williams O, DeSorbo A, Noble J, et al. Child-mediated stroke communication: findings from hip hop stroke. Stroke 2012;43:163-9.

5. Shigehatake Y, Yokota C, Amano T, et al. Stroke education using an animated cartoon and a manga for junior high school students. $J$ Stroke Cerebrovasc Dis 2014;23:1623-7.

6. Ishigami K, Yokota C, Nishimura K, et al. Delivering knowledge of stroke to parents through their children using a Manga for stroke education in elementary school. J Stroke Cerebrovasc Dis 2017;26:431-437

7. Kothari RU, Pancioli A, Liu T, et al. Cincinnati prehospital stroke scale: reproducibility and validity. Ann Emerg Med 1999;33:373-8.

8. Miyashita F, Yokota C, Nishimura K, et al. The effectiveness of a stroke educational activity performed by a schoolteacher for junior high school students. J Stroke Cerebrovasc Dis 2014;23:1385-90.

9. Ohyama S, Yokota C, Miyashita F, et al. Effective education materials to advance stroke awareness without teacher participation in junior high school students. J Stroke Cerebrovasc Dis 2015;24:2533-8.

10. Morgenstern LB, Gonzales NR, Maddox KE, et al. A randomized, controlled trial to teach middle school children to recognize stroke and call 911: the kids identifying and defeating stroke project. Stroke 2007:38:2972-8.

11. Foster GD, Linder B, Baranowski T, et al. A school-based intervention for diabetes risk reduction. N Engl J Med 2010;363:443-53.

12. Cai L, Wu Y, Wilson RF, et al. Effect of childhood obesity prevention programs on blood pressure: a systematic review and meta-analysis. Circulation 2014;129:1832-9.

13. Agyeman $\mathrm{O}$, Nedeltchev $\mathrm{K}$, Arnold M, et al. Time to admission in acute ischemic stroke and transient ischemic attack. Stroke 2006;37:963-6.

14. Demaerschalk BM, Bobrow BJ, Paulsen M. Phoenix, Operation Stroke Executive Committee: development of a metropolitan matrix of primary stroke centers: the Phoenix experience. Stroke 2008;39:1246-53.

15. Gladstone DJ, Rodan LH, Sahlas DJ, et al. A citywide prehospital protocol increases access to stroke thrombolysis in Toronto. Stroke 2009;40:3841-4.

16. Bray JE, Martin J, Cooper G, et al. An interventional study to improve paramedic diagnosis of stroke. Prehosp Emerg Care 2005;9:297-302.

17. Hsieh $\mathrm{HC}$, Hsieh $\mathrm{CY}$, Lin $\mathrm{CH}$, et al. Development of an educational program for staffs of emergency medical service to improve their awareness of stroke within 3 hours of symptom onset: a pilot study. Acta Neurol Taiwan 2013;22:4-12.

18. Frendl DM, Strauss DG, Underhill BK, et al. Lack of impact of paramedic training and use of the cincinnati prehospital stroke scale on stroke patient identification and on-scene time. Stroke 2009;40:754-6.

19. Caceres JA, Adil MM, Jadhav V, et al. Diagnosis of stroke by emergency medical dispatchers and its impact on the prehospital care of patients. J Stroke Cerebrovasc Dis 2013;22:e610-14.

20. Fussman C, Rafferty AP, Lyon-Callo S, et al. Lack of association between stroke symptom knowledge and intent to call 911: a population-based survey. Stroke 2010;41:1501-7.

21. Marto JP, Borbinha C, Filipe R, et al. Impact of stroke education on middle school students and their parents: a cluster randomized trial. Int J Stroke 2017;12:401-11. 